\title{
Image Case: Sausage Shaped Stone Extraction from the Common Bile Duct
}

\author{
Mohamed I Radwan, Mohamed H Emara, Ibrahim M Ibrahim \\ Tropical Medicine Department, Faculty of Medicine, Zagazig University, Zagazig, \\ Egypt
}

Corresponding author: Mohamed I Radwan email:drmmagdy@yahoo.c om

mobile:

$+201118862897$

Received : $14 / 11$

12012

Accepted after

revision: $20 / 11 / 2012$
A 60-year old male patient presented with recurrent obstructive jaundice. He gave history of chronic hepatitis $\mathrm{C}$ and cholecystectmy. When presented for the current episode of obstructive jaundice his lab was bilirubin total $5.1 \mathrm{mg} / \mathrm{dl}$, bilirubin direct $4.1 \mathrm{mg} / \mathrm{dl}$, prothrombin concentration 77\%, Haemoglobin 11 gm\%. ERCP showed oblong filling defect involving the lower one third of common bile duct. Extrcation balloon extracted this large stone that appears sausage shaped emerging from the duodenal papilla after precut sphincterotomy.

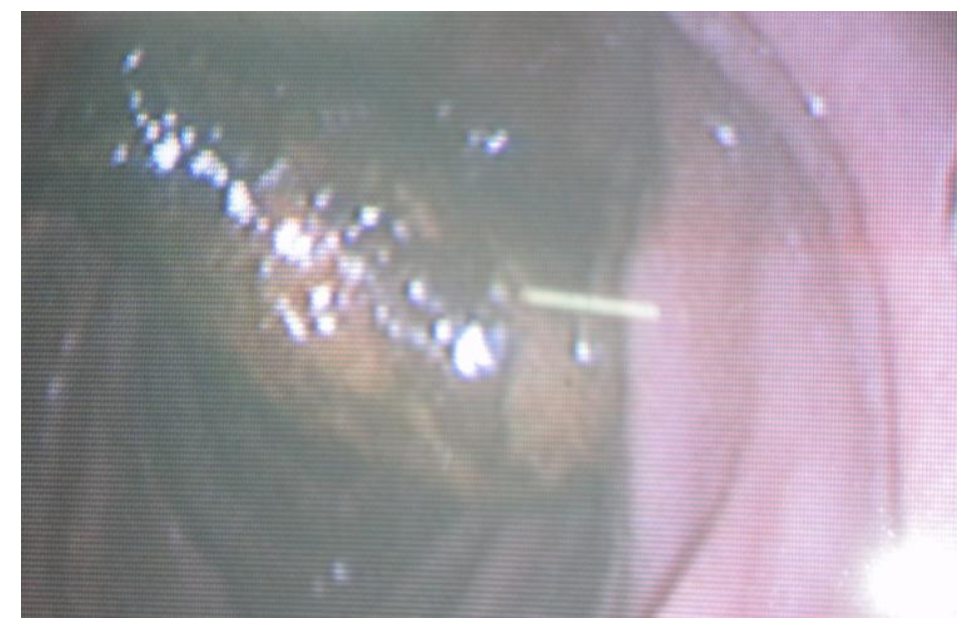

